\title{
Ankle Rocking Training and Functional Abilities in Children with Cerebral Palsy
}

Amira M. Eltohamy ${ }^{1}$, Mahmoud A. Mahran², Mohamed I. Elassal ${ }^{1}$, Ahmed H. Kamel*1

${ }^{1}$ Department of Physical Therapy for Pediatric Disorders and its Surgery, Faculty of Physical Therapy, Cairo University, Egypt. ${ }^{2}$ Department of Orthopedic Surgery, Pediatric Orthopedics and Limb Reconstruction Surgery Unit, Ain Shams University, Egypt.

*Corresponding author: Ahmed H. Kamel, Mobile: (+20) 01113203945, E-Mail: ahmedhany191991@gmail.com@gmail.com

\begin{abstract}
Background: Children with a physical disability are known to be at higher risk of an inactive life style. The hip, knee, and ankle joints have different roles depending on the phase of walking and running. They must work together to produce and absorb forces to allow efficient movement through the stance phase. In walking there are three rockers: the heel rocker, the ankle rocker, and the forefoot rocker.

Objective: The aim of the study was to investigate the effect of ankle rocking training on the development of gross motor functional abilities in children with cerebral palsy.

Patients and methods: Thirty children diagnosed as spastic cerebral palsy according to gross motor classification system, (Grade II \& III GMFCs) were selected from the Outpatient Clinic, Faculty of Physical Therapy, Cairo University. The children' ages ranged from three to six years old from both sexes. This was a cross-sectional study where the selected cerebral palsied children were divided into two groups (control group and study group). The control group received traditional gait training and standing program, while the study group received the same traditional gait training and standing program in addition to gait training using ankle rocker device. Both groups received treatment program 3 times/week for three consecutive months for one hour per session.
\end{abstract}

Results: It was revealed that there was a significance difference within each single group (the pre- and post-treatment) and between both groups.

Conclusion: According to the current study results, there was a highly significant difference within the study group preand post-treatment and between groups in favour of the study group because of ankle rocking training.

Keywords: Cerebral Palsy, Ankle Rockers, Rocking training, Hand-held Dynamometer, Foot Posture Index-6, Functional Abilities.

\section{INTRODUCTION}

Cerebral palsy (CP) is a neurological disorder caused by abnormalities in the developing brain of infants and children. CP leads to an impairment of muscle coordination in the body and movement control (1). Cerebral palsy (CP) is the most common childhood motor disability and often results in debilitating walking abnormalities, such as flexed-knee and stiff-knee gait ${ }^{(2)}$. The ability to maintain and control the body center of mass within the base of support to prevent falls and complete desired movements, is known as postural stability. The control of postural stability involves a system of intricately associated neuromuscular mechanisms of a high degree of complexity, which is maintained by proprioceptive, vestibular and visual feedback. Three basic coordination patterns of standing: ankle strategy, hip strategy, and stepping strategy have been described in both adults and children ${ }^{(3)}$.

In walking there are three rockers: the heel rocker, the ankle rocker, and the forefoot rocker. While foot position at initial contact in running has been extensively studied, little research has framed foot and ankle motion in running in context of the foot rockers even though at slow running speeds, 80 to $90 \%$ of runners' heel strike and exhibit all three rockers ${ }^{(4)}$.

The aim of the study was to investigate the effect of ankle rocking training on the development of gross motor functional abilities in children with cerebral palsy. PATIENTS AND METHODS
A cross-sectional study that included thirty children from both sexs diagnosed as spastic cerebral palsy. They were selected from the outpatient clinic of the Faculty of Physical Therapy, Cairo University. The study was conducted through the period from September 2020 and March 2021. They were classified as GMFCs II and III. They were assigned into two groups: Study group and control group respectively, after fulfilling the inclusion criteria. Functional abilities, muscle power and foot posture were assessed for both groups before and after performing traditional physiotherapy programs with and without using rocker instrument.

Inclusion criteria: Patients' age ranged from 3 to 6 years old. The diagnosis of these children was established according to gross motor classification system (Grade II \& III GMFCs).

Exclusion criteria: Botox injection in the last 6 months. Surgical procedures in the last 12 months. Musculoskeletal contractures. Visual or other sensoryinput impairments.

\section{Ethical approval:}

The whole procedure was explained for every parent. Each parent signed informed consent before beginning of the study to insure complete satisfaction. The Ethical Committee of Faculty of Physical Therapy, Cairo University approved this study. This work has been carried out in accordance with The Code of Ethics of the World Medical 
Association (Declaration of Helsinki) for studies involving humans.

\section{Procedures:}

A-For evaluation:

\section{The Peabody Developmental Gross Motor Scale (PDMS-GM):}

This study was concerning only stationary and locomotion subtests. Items are scored on a three-point scale $(0,1 \& 2)$, with a score of 1 indicating that the behavior is emerging but that the criterion for successful performance is not fully met. The raw score for the gross motor scale can be converted into an age-equivalent, a percentile, or a standardized score. The raw score may also be converted into a scaled score. Scaled scores are normalized raw scores that are independent of age norms and, therefore, capable of measuring small changes in motor development. Scaled scores have a mean of 500, a standard deviation of 100 , and a range of 200 to 800 . A scaled score of 500 indicates that a child is at the midpoint in mastery of the items on the PDMS-GM but does not indicate what items were achieved ${ }^{(5)}$.

\section{Foot posture index:}

The patient should stand on their relaxed stance position with their arms by the side in double limb support. It may be helpful to ask the patient to take several steps, marching on the spot prior to settling into a comfortable stance position. The assessor needs to be able to move around the patient during the assessment and to have uninterrupted access to the posterior aspect of the leg and foot. If an observation cannot be made (e.g. because of soft tissue swelling) simply miss it out and indicate on the datasheet that the item was not scored. If there was genuine doubt about how high or low to score an item always use the more conservative score. Features commensurate with an approximately neutral foot posture were graded as zero, while pronated postures were given a positive value, and supinated features as negative value. When the scores were combined, the aggregate value gives an estimate of the overall foot posture. high positive aggregate values indicate a pronated posture, significantly negative aggregate values indicate a supinated overall foot posture, while for a neutral foot the final FPI aggregate score should lie somewhere around zero ${ }^{(6)}$.

\section{The hand-held dynamometer:}

a hand-held dynamometer measures maximum voluntary isometric contraction as muscular strength over a range from 0 to $60 \mathrm{Kg}$-force. The proper positions were shown to the participants at least twice before performing the measurement to help them understand the task. Subjects were instructed to exert maximal effort against the dynamometer, avoiding explosive movements. Strength was measured as the peak force that the examiner had to apply to break the isometric contraction, indicated by a slight movement of the subject's leg in the direction opposite to the voluntary movement. Measurements were repeated twice at intervals of about 30 seconds. The same order of testing was maintained throughout the sessions ${ }^{(7)}$.

\section{B-For Treatment:}

1- A designed Rocker training instrument:

Its shape helps in rocking action providing springs, which leads to a curve that is similar to heel strike and pre-swing gait sub-phases. Using 3 springs triangular in shape is adequate for this aim, this obligates child to use rocking of ankle.

\section{2- Traditional gait training and standing program:}

- Flexibility training: Flexibility exercises for calf muscles can increase range of motion in patients with limited range of mobility (ROM) and poor balance.

* Strength training: For all antigravity muscles.

* Gait training: Walking in a manner of closed environment, walking in all directions; forward, backward, and sideways, and obstacles will be used on the walkway inside and outside.

* Balance training program by kneeling on the balance board, standing on the balance board, one leg stance on the balance board, walking on balance board, walking on balance beam, and walking on balance board with obstacles on it.

Statistical analysis: Statistical analysis was conducted using SPSS for windows, version 26 (SPSS, Inc., Chicago, IL). Prior to final analysis, data were screened for normality assumption, homogeneity of variance, and presence of extreme scores. This exploration was done as a pre-requisite for parametric calculations of the analysis of difference. Preliminary assumption checking revealed that data were not normally distributed for all measured variables, as assessed by Shapiro-Wilk test $(\mathrm{p}<0.05)$. There was homogeneity of variances $(\mathrm{p}>$ $0.05)$ and co-variances ( $p>0.05$ ), as assessed by Levene's test of homogeneity of variances. Accordingly, non-parametric statistics were used. The Mann-Whitney $\mathrm{U}$ test was used to compare whether there is a difference in the dependent variable for the two independent groups. While, Wilcoxon test was used to compare whether there is a difference within the same group. Unpaired t-test was used to compare whether there is a difference pretreatment in the demographic characteristics for the two study groups. Chi-squared test was carried out for comparison of gender distribution between groups. The alpha level was set at 0.05.

\section{RESULTS}

The baseline characteristics of the participants showed that no statistically significant differences existed between both groups $(\mathrm{P}>0.05)$ including age, height, weight and BMI, as shown in table (1). There was also, no significant difference between both groups regarding gender $(\mathrm{P}>0.05)$.

Pretreatment comparison between both the groups: no statistically significant differences were noticed regarding the pretreatment between the two groups in all measured variables $(\mathrm{P}>0.05)$ as shown in table (2).

Concerning pre-treatment and post-treatment comparison in each group, there was a significant improvement in all measured variables $(\mathrm{P}<0.05)$ in the study group, while the control group showed significant improvement in all 
measured variables except in hand-held dynamometer (Right tibialis anterior muscle, Right and left calf muscles there were no significant improvement) as shown in table (2).
Post-treatment comparison between both the groups: There was statistically significant improvement in all measured variables between both groups $(\mathrm{P}<0.05)$ in favor to study group as shown in table (2).

Table (1): General characteristics of participants in both groups

\begin{tabular}{lccc}
\hline & $\begin{array}{c}\text { Control group } \\
\overline{\mathbf{x}} \pm \mathbf{S D}\end{array}$ & $\begin{array}{c}\text { Study group } \\
\overline{\mathbf{x}} \pm \mathbf{S D}\end{array}$ & P- value \\
\hline Age $($ Years) & $5.43 \pm 1.09$ & $5.53 \pm 1.04$ & 0.8 \\
Height $(\mathbf{c m})$ & $22.86 \pm 3.33$ & $24.23 \pm 2.65$ & 0.22 \\
Weight $(\mathbf{k g})$ & $115.73 \pm 8.19$ & $118.26 \pm 7.13$ & 0.37 \\
BMI $\left(\mathbf{k g} / \mathbf{m}^{2}\right)$ & $17.23 \pm 0.95$ & $17.34 \pm 1.42$ & 0.82 \\
Gender & & & \\
Boys & $7(46.66 \%)$ & $6(40 \%)$ & 0.713 \\
Girls & $8(53.33 \%)$ & $9(60 \%)$ & \\
\hline
\end{tabular}

P-value: probability value;

*Significant at $\mathrm{P}<0.05$

Table (2): Comparison between both groups in all measured variables

\begin{tabular}{|c|c|c|c|c|c|}
\hline \multicolumn{2}{|c|}{ Variable } & Time & $\begin{array}{c}\text { Control group } \\
\overline{\mathbf{x}} \pm \mathrm{SD}\end{array}$ & $\begin{array}{c}\text { Study group } \\
\overline{\mathbf{x}} \pm \mathrm{SD}\end{array}$ & $\begin{array}{c}\text { P- } \\
\text { Value }\end{array}$ \\
\hline \multirow{4}{*}{ 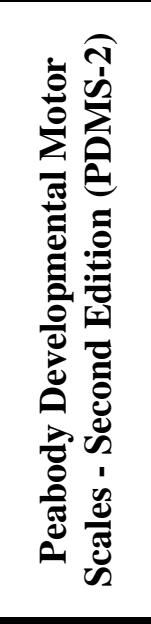 } & Sum standard score & $\begin{array}{c}\text { Before } \\
\text { After } \\
\text { P Value }\end{array}$ & $\begin{array}{c}3.86 \pm 1.0 \\
4.33 \pm 0.81 \\
\text { 0.01* }\end{array}$ & $\begin{array}{c}3.66 \pm 0.9 \\
5.2 \pm 1.26 \\
\mathbf{0 . 0 0 0 1 *}\end{array}$ & $\begin{array}{c}0.56 \\
\text { 0.03* }\end{array}$ \\
\hline & Age equivalent (score) & $\begin{array}{c}\text { Before } \\
\text { After } \\
\text { P Value }\end{array}$ & $\begin{array}{c}21.16 \pm 1.09 \\
21.93 \pm 0.88 \\
\text { 0.01* }\end{array}$ & $\begin{array}{c}20.63 \pm 2.06 \\
23.43 \pm 2.25 \\
\mathbf{0 . 0 0 0 1} *\end{array}$ & $\begin{array}{c}0.38 \\
\text { 0.02* }\end{array}$ \\
\hline & Quotient (score) & $\begin{array}{c}\text { Before } \\
\text { After } \\
\text { P Value }\end{array}$ & $\begin{array}{c}42.33 \pm 1.67 \\
43.46 \pm 0.83 \\
\text { 0.01* }\end{array}$ & $\begin{array}{c}43.2 \pm 2.42 \\
46.6 \pm 2.0 \\
\text { 0.0001* }\end{array}$ & $\begin{array}{c}0.26 \\
\text { 0.0001* }\end{array}$ \\
\hline & $Z$ score & $\begin{array}{c}\text { Before } \\
\text { After } \\
\text { P Value }\end{array}$ & $\begin{array}{c}4.2 \pm 0.5 \\
4.13 \pm 0.48 \\
\mathbf{0 . 0 1} *\end{array}$ & $\begin{array}{c}4.17 \pm 0.75 \\
3.48 \pm 0.15 \\
\mathbf{0 . 0 0 3}^{*}\end{array}$ & $\begin{array}{c}0.9 \\
\text { 0.0001* }\end{array}$ \\
\hline \multirow{2}{*}{ 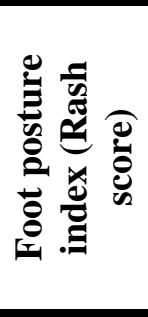 } & Right & $\begin{array}{c}\text { Before } \\
\text { After } \\
\text { P Value }\end{array}$ & $\begin{array}{c}4.73 \pm 0.74 \\
3.66 \pm 0.83 \\
\mathbf{0 . 0 0 5}^{*} \\
\end{array}$ & $\begin{array}{c}4.78 \pm 0.78 \\
2.95 \pm 0.95 \\
\text { 0.0001* } \\
\end{array}$ & $\begin{array}{c}0.844 \\
\mathbf{0 . 0 3 7} *\end{array}$ \\
\hline & Left & $\begin{array}{c}\text { Before } \\
\text { After } \\
\text { P Value }\end{array}$ & $\begin{array}{c}4.34 \pm 0.71 \\
3.58 \pm 0.59 \\
\mathbf{0 . 0 0 9 *} \\
\end{array}$ & $\begin{array}{c}4.45 \pm 0.64 \\
2.85 \pm 1.01 \\
\text { 0.0001* }\end{array}$ & $\begin{array}{c}0.653 \\
\mathbf{0 . 0 2 1}^{*}\end{array}$ \\
\hline \multirow{4}{*}{ 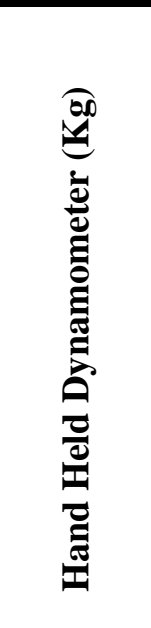 } & $\begin{array}{c}\text { Tibialis anterior muscle } \\
\text { (Right) }\end{array}$ & $\begin{array}{c}\text { Before } \\
\text { After } \\
\text { P Value }\end{array}$ & $\begin{array}{c}1.52 \pm 0.45 \\
1.60 \pm 0.35 \\
0.111\end{array}$ & $\begin{array}{c}1.44 \pm 0.3 \\
2.09 \pm 0.45 \\
\text { 0.0001* }\end{array}$ & $\begin{array}{c}0.196 \\
\mathbf{0 . 0 0 3}^{*}\end{array}$ \\
\hline & $\begin{array}{c}\text { Tibialis anterior muscle } \\
\text { (Left) }\end{array}$ & $\begin{array}{c}\text { Before } \\
\text { After } \\
\text { P Value }\end{array}$ & $\begin{array}{c}1.42 \pm 0.25 \\
1.60 \pm 0.15 \\
\mathbf{0 . 0 1} * \\
\end{array}$ & $\begin{array}{c}1.36 \pm 0.46 \\
2.18 \pm 0.69 \\
\text { 0.0001* } \\
\end{array}$ & $\begin{array}{c}0.243 \\
\mathbf{0 . 0 0 4} *\end{array}$ \\
\hline & Calf muscle (Right) & $\begin{array}{c}\text { Before } \\
\text { After } \\
\text { P Value }\end{array}$ & $\begin{array}{c}1.96 \pm 0.60 \\
2.02 \pm 0.52 \\
0.167 \\
\end{array}$ & $\begin{array}{c}1.83 \pm 0.53 \\
2.75 \pm 0.51 \\
\text { 0.0001* } \\
\end{array}$ & $\begin{array}{c}0.285 \\
\text { 0.001* }\end{array}$ \\
\hline & Calf muscle (Left) & $\begin{array}{c}\text { Before } \\
\text { After } \\
\text { P Value }\end{array}$ & $\begin{array}{c}1.71 \pm 0.64 \\
1.85 \pm 0.56 \\
0.189\end{array}$ & $\begin{array}{c}1.79 \pm 0.58 \\
3.10 \pm 0.56 \\
\text { 0.0001* }^{*}\end{array}$ & $\begin{array}{c}0.125 \\
\text { 0.001* }\end{array}$ \\
\hline
\end{tabular}




\section{DISCUSSION}

This study was conducted to investigate the effect of ankle rocking training on the development of gross motor functional abilities in children with cerebral palsy. Thirty children with spastic cerebral palsy classified as GMFCs II,III were assigned into two groups study group and control group respectively. Functional abilities, muscle power and foot posture were assessed for both groups before and after performing traditional physiotherapy programs with and without using rocker instrument. Functional abilities were assessed by The Peabody Developmental Gross Motor Scale (PDMS-GM), 2nd edition (PDMS-

2). Muscle power was assessed by hand-held dynamometer and foot posture was assessed using foot posture index (FPI-6).

Cerebral palsy (CP) is a neurological disorder caused by abnormalities in the developing brain of infants and children. CP leads to an impairment of muscle coordination in the body and movement control. The worldwide prevalence of $\mathrm{CP}$ is 1.5 to 4 per 1,000 live births ${ }^{(2)}$

Postural control is a critical factor in performing routine activities of daily life, although it is an automatic process for optimal health. It is oftentimes a challenging goal for children with vestibular impairment, with cerebral palsy, and others with pathology or injury. For instance, children with cerebral palsy frequently have an impaired sense of equilibrium, abnormal motor control, persistence of primitive reflexes, and may develop abnormal posturing ${ }^{(3)}$.

Postural control may be attributed to coordination of hip protraction/retraction, ankle control, and foot intrinsic muscle activity ${ }^{(3)}$. Children with a physical disability are known to be at higher risk of an inactive lifestyle ${ }^{(8)}$. The hip, knee, and ankle joints have different roles depending on the phase of walking and running. They must work together to produce and absorb forces to allow efficient movement through the stance phase ${ }^{(4)}$.

In walking there are three rockers: the heel rocker, the ankle rocker, and the forefoot rocker. While foot position at initial contact in running has been extensively studied, little research has framed foot and ankle motion in running in context of the foot rockers even though at slow running speeds, 80 to $90 \%$ of shod runners' heel strike and exhibit all three rockers ${ }^{(4)}$.

The results of the current study revealed that there were significant differences between groups and within each group. The PDMS-2 can be used as a set of evaluative tools for children suffering from $\mathrm{CP}{ }^{(9)}$. The Peabody Developmental Motor Scales-2 (PDMS-2) was developed by authors whose backgrounds were in education and physical education. The scales were developed with the intent to identify children whose gross and fine motor skills are delayed or aberrant relative to the normative group, allow for comparison of abilities both within and between the 2 motor areas assessed (Gross motor and Fine motor), enable performance to be measured across time or in response to a specific intervention, be appropriate for use with children having motor handicaps, and provide a mechanism which would link assessment and programming when used in conjunction with the activity cards. The Peabody Developmental Motor Scales-2 (PDMS-2) as an assessment tool was being used to diagnose and plan treatment for a child ${ }^{(\mathbf{1 0})}$.

The results of the current study revealed that there was significant differences pre- and posttreatment using the FPI-6. These significant differences toward decreased scores which mean feet tend to counteract the excessive pathological pronation. This decrease in FPI-6 rasch scores and raw scores may be due to using of the rocker instrument, which mainly focusing on training of foot rockers especially rear foot rockers as it resembles the major problem. All CP children had a higher load on the forefoot, and revealed a higher incidence of flat feet (11).

Our results agree with Redmond $\boldsymbol{e t}$ al. ${ }^{(12)}$ who found that tendency toward more pronated foot postures in younger children is also well documented. A flatter, more pronated foot has been reported in young children as a consequence of the process of development of the longitudinal arch. Using the FPI-6 would contribute to a better understanding of the development of the foot during growth. The FPI-6 offers a three-dimensional assessment of pronation and supination, unlike traditional bi-planar techniques such as footprint examination or radiography. These data can also be used, in conjunction with those provided by future studies of foot symptomatology to better determine what should be considered physiological or pathological as regards foot posture in childhood ${ }^{(13)}$.

Abnormal foot postures are caused by muscle spasticity and imbalance, soft-tissue contractures, bony torsion and joint instability ${ }^{(\mathbf{1 4})}$. All CP children had a higher load on the forefoot, and diplegics revealed a higher incidence of flat feet. Increased plantar pressure values were found in both forefoot (for all patients) and midfoot (excluding left hemiplegics). This increased midfoot contact area with reduced rearfoot load can be seen as an indicator of extreme flatfoot, as it is seen in the midfoot break. A probable cause is loading of the foot with the toes first, as it occurs in patients with cerebral palsy due to either equinus foot position or knee flexion posture and lack of foot protection by orthotics. The strategies used, equinus foot or knee flexion posture, may also be seen as an attempt to compensate for poor stability of posture, which is common in $\mathrm{CP}^{(\mathbf{1 1})}$.

There was highly significant difference between pre- and post-treatment using hand-held dynamometer on anterior tibial muscles group, which mean increased anterior tibial muscles group strength. Is increased muscle strength the only factor that determines motor development of a case? Studies on the relationship between gross motor development and muscle power found that the more muscle strength, the 
more PDMS-2 gross motor scores. This suggests that there is a strong relation between muscle power and functional abilities according to Eek $\boldsymbol{e t}$ al. ${ }^{(15)}$ who suggested that ankle dorsi-flexion power increases likely due to terms of the human body being a system where activation of one muscle group also requires activation of the other muscle groups needed for stabilization of adjacent joints. This stabilizing mechanism may give a training effect and can explain why muscle strength in the ankle plantar-flexion is increased ${ }^{(15)}$.

\section{CONCLUSION}

According to the current study results, there was a highly significant difference within the study group pre and post treatment and between groups in favour of the study group because of ankle rocking training.

\section{Financial support and sponsorship: Nil.}

\section{Conflict of interest: Nil.}

\section{REFERENCES}

1. Rose J, Cahill-Rowley K, Butler E (2017): Artificial Walking Technologies to Improve Gait in Cerebral Palsy: Multichannel Neuromuscular Stimulation. Artificial Organs, 41 (11): 233-239.

2. Shroff G, Barthakur K, Mohan P et al. (2015): Single Photon Emission Computed Tomography Scan as a Diagnostic Tool in Children with Cerebral Palsy Treated with Human Embryonic Stem Cells. Nucl Med Radiat Ther., 6 (4): 237-40.

3. Ferdjallah M, Harris G, Smith $P$ et al. (2002): Analysis of postural control synergies during quiet standing in healthy children and children with cerebral palsy. Clinical Biomechanics, 17 (3): 203-210.

4. Dugan S, Bhat K (2005): Biomechanics and analysis of running gait. Physical Medicine and Rehabilitation Clinics of North America, 16 (3): 603-621.

5. Palisano R, Kolobe T, Haley $\mathbf{S}$ et al. (1995): Validity of the Peabody Developmental Gross Motor Scale as an
Evaluative Measure of Infants Receiving Physical Therapy. Physical Therapy, 75 (11): 939-948.

6. Morrison S, Ferrari J (2009): Inter-rater reliability of the Foot Posture Index (FPI-6) in the assessment of the paediatric foot. Journal of Foot and Ankle Research, 2 (1): $1-5$.

7. Bandinelli S, Benvenuti E, Del Lungo I et al. (1999): Measuring muscular strength of the lower limbs by hand-held dynamometer: A standard protocol. Aging Clinical and Experimental Research, 11 (5): 287-293.

8. Bloemen M, Van Wely L, Mollema J et al. (2017): Evidence for increasing physical activity in children with physical disabilities: a systematic review. Developmental Medicine \& Child Neurology, 59 (10): 1004-1010.

9. Wang H, Liao H, Hsieh C (2006): Reliability, Sensitivity to Change, and Responsiveness of the Peabody Developmental Motor Scales-Second Edition for Children with Cerebral Palsy. Physical Therapy, 86 (10): 1351-1359.

10. Tripathi R, Joshua A, Kotian M et al. (2008): Normal Motor Development of Indian Children on Peabody Developmental Motor Scales-2 (PDMS-2): Pediatric Physical Therapy, 20 (2): 167-172.

11. Saxena S, Rao B, Kumaran S (2014): Analysis of postural stability in children with cerebral palsy and children with typical development: An observational study. Pediatric Physical Therapy, 26 (3): 325-330.

12. Redmond A, Crane Y, Menz H. (2008): Normative values for the Foot Posture Index. Journal of Foot and Ankle Research, 1 (1): 6-9.

13. Gijon-Nogueron G, Montes-Alguacil J, AlfagemeGarcia P et al. (2016): Establishing normative foot posture index values for the paediatric population: a cross-sectional study. Journal of Foot and Ankle Research, 9 (1): 24-28.

14. Church $\mathrm{C}$, Lennon $\mathrm{N}$, Alton $\mathrm{R}$ et al. (2017): Longitudinal change in foot posture in children with cerebral palsy. Journal of Children's Orthopaedics, 11 (3): 229-236.

15. Eek M, Tranberg R, Zügner $\mathbf{R}$ et al. (2008): Muscle strength training to improve gait function in children with cerebral palsy. Developmental Medicine \& Child Neurology, 50 (10): 759-764. 